\title{
A study on the risk compensation mechanism of enterprise technological innovation
}

\author{
Jiaying Chen, Shaojiang Lin * \\ Sichuan Agricultural University, Sichuan, China \\ *Corresponding author Email: linshaojiang@163.com
}

\begin{abstract}
Technology innovation is the main source for the growth of modern economy, at the same time, technological innovation is a high-risk activity, which cannot achieve the expected technical and economic indicators because of the uncertainty of the external environment, the technological innovation projects, as well as the difficulty and complexity of technology innovation activities plus the limited enterprise's ability and strength. This will lead to financial risk and cause the tangible economic losses to the enterprise. In this paper, it will take the connotation of enterprise technology innovation risk as breakthrough point, based on the analysis on the risk factors of the enterprise technology innovation, it discusses the composition of the technology innovation risk compensation system, at the same time, and it also discusses the operation mechanism of the technology innovation risk compensation system.
\end{abstract}

Keywords: technological innovation; risk compensation; economic management.

\section{Introduction}

In recent years, under the background that the country vigorously promoted strategy of revitalizing by science and technology, as well as the background of promoting the independent innovation strategy, the enterprises have great awareness about the technological innovation and pay much attention to the extend of the technological innovation. However, because the enterprise should invest a lot in the technological innovation, compared with the developed countries, there is still a significant gap between them. One reason is due to the thinking and understanding; on the other hand, another reason is that the technology development level of most of the enterprises in our country is low, capital accumulation is not strong as well as some other reasons. At the same time, there is a close relationship with the environment of technology innovation in China, which is not so sound and perfect. For example, the technology innovation policy support is insufficient, the technology innovation risk compensation system is not perfect and so on, which can seriously affect the enterprise technology innovation activities. Moreover, because the technological innovation of the enterprise is a high investment with high risk, once the enterprise innovation is failed, it may suffer huge losses or become even bankruptcy. Therefore, the government should have have a full range of risk compensation for the technological innovation of enterprises. In this paper, it mainly explores the risk compensation system for the technology innovation and makes the specialized research, in order to improve and perfect our country's technical innovation external environment, so as to further promote the majority of enterprises and increase the technological innovation to provide theoretical guidance and policy decision support.

\section{The Connotation of Enterprise Technological Innovation Risk}

Technological innovation is a kind of risk behavior, the enterprise's technological innovation behavior has the feature of symmetry with the survival risk, on one hand, the enterprise may get huge profits brought the technological innovation, on the other hand, it may bear the corresponding risks. [1] In 1994, Professor Xie Kefan defined technology innovation risk as follows: due to the uncertainty of the external environment, the difficulty and complexity of the technological innovation of the projects, as well as the limited innovator's own ability and capability, which leads to the failure of technological innovation, suspended, revoked or not up to the target probability and consequences 
(see Fig. 1). And the enterprise technology innovation is driven by the enterprise under the market mechanism, in order to obtain high returns or core competitiveness, the enterprises will take the initiative to carry out technological innovation behavior. Moreover, the enterprise technology innovation risk is not limited to the technological innovation project, which is caused by the enterprise technical innovation projects and then it can spread to the entire enterprise. [2] Therefore, the risk of technological innovation can be defined as the risk because of the failure of enterprise technological innovation projects, as well as the sum of the other chain risks that may be caused.

Technological Innovation Risk Benefits

\begin{tabular}{|c|c|c|c|c|c|c|c|}
\hline \multicolumn{8}{|l|}{8000} \\
\hline \multicolumn{8}{|l|}{7500} \\
\hline \multicolumn{8}{|l|}{7000} \\
\hline \multicolumn{8}{|l|}{6500} \\
\hline \multicolumn{8}{|l|}{6000} \\
\hline & 1 & 2 & 3 & 4 & 5 & 6 & 7 \\
\hline
\end{tabular}

Time(Year)

Independent Innovation Benefits

Fig.1 The Chart of Technological Innovation Risk Benefits

\section{Risk Factors Analysis of Enterprise Technological Innovation}

There are many factors that can affect the success or failure of technological innovation, Generally, it can be divided into two categories: the internal risk and the external risk. The internal risk of enterprise mainly refers to the management risk and technical risk, producing risk and financial risk and so on, while the external risk of enterprises are mainly including policy risks and market risks, etc.. [3]

\section{The Internal Risk of Enterprise}

\subsection{Management Risk}

Technological innovation management risk refers to the possibility that the failure of innovation may be occurred during the process of technological innovation. For example, the poor organization and coordination is existed, some departments are not good at cooperating, leaders do not pay enough attention to the risk, there is no sufficient research, the distortion of market information is existed, the leader of the main body of innovation made wrong decision-making, market positioning is not right, the researching and development process is uncoordinated. [4,5]

\subsection{Technical Risks}

Technology risk mainly refers to the risk that is caused by the technological innovation projects, for example the technology is not mature and perfect, the leading level of technology is not enough, and the risks brought by some new technology that cannot be replaced. During the process of technological innovation, the uncertainty and the life cycle of technology are the main important factors that can affect the success of technological innovation. [6]

\subsection{Producing Risk}

The producing risk of technological innovation refers the possibility of failure of innovation that may be occurred during the process of technological innovation. For example, it is difficult to achieve mass production, the producing cycle is too long, the producing process is not reasonable, the damage appeared on the equipment and instruments, the detecting means is backward, it is difficult to 
guarantee the quality of products, the reliability is poor, the supply system is unable to meet the requirements of mass production, etc.

\subsection{Financial Risks}

The financial risk of technological innovation refers the possibility of interruption caused by the interruption without supplying enough funds timely in technical innovation activities. [7] Enterprise technological innovation requires a great deal of money, since each link cannot be interrupted, thus, it must be guaranteed with enough money supply, so as to make innovation activities continue. Because the difficulties in the operation of the enterprise can be occurred, or the need of technical innovation cannot be raised, it may lead to the failure of technological innovation.

\section{The External Risk of Enterprise}

\subsection{Policy Risks}

The policy risk of technological innovation refers to the possibility of the failure of social politics, state or local laws, regulations, policies, etc.. For example, the policy is not in conformity with the national or local government's environmental protection policies, as well as energy policy, science and technology policy, which can not get the imported license to buy some products, raw materials, equipment, as well as technology, etc.. [8-9]

\subsection{Market Risks}

The market risk of technological innovation refers to the possibility that the new product may not fit for the market demand or the changes which may not be accepted by the market after the technological innovation. The main cause of market risk is the uncertainty of the market; the existence of the risk is sourced by the uncertainty of the ever-changing market, the consumer preference, the impact on technology introduction, the existence of the imitators as well as the violations that are frequently occurred [10].

\section{The Composition of Risk Compensation System of Technological Innovation}

Generally speaking, the risk compensation system of technical innovation can be made up of five parts, which can be shown in Fig. 2. (1) The loss compensation of enterprise innovation . Enterprise is the main part of the technological innovation and it can be regarded as the first body, the technological innovation activities of enterprises can be affected by the impact of technology, capital, market and legal protection, as well as some other uncertain factors, which is a great risk. At the same time, the technological innovation activities of all participants and enterprises have to bear most of the risks brought by the technological innovation activities. Therefore, the technological innovation activities of enterprises should give direct compensation, which is the most effective and essential as well as important way of compensation. (2)Science and technology insurance compensation. Science and technology insurance is a kind of activity proposed and launched by the State Ministry of Science and Technology as well as China Insurance Regulatory Commission in late 2006, so as to provide insurance services to high-tech enterprises and support the development of high-tech enterprises, which can ultimately promote the implementation of the national strategy of independent innovation. Technology insurance compensation can be including the compensation for insurance companies involved in scientific and technological innovation activities, the compensation for the purchase of insurance premiums paid by enterprises that are in the purchase of scientific and technological innovation. (3) The compensation for the loan bank. Enterprise's technological innovation activities should need a lot of capital investment, among them, bank loans is one of the main channels. But in order to avoid the risk, banks are often reluctant to loan funds to these enterprises, therefore, the enterprises have to bear the increased risk of money in the technological innovation activities, which can hinder the technological innovation activities of enterprises. Therefore, in the technical innovation risk compensation system, it should give the appropriate compensation to the loan bank that provide loan for the scientific and technological innovation according to the loan amount and frequency. 


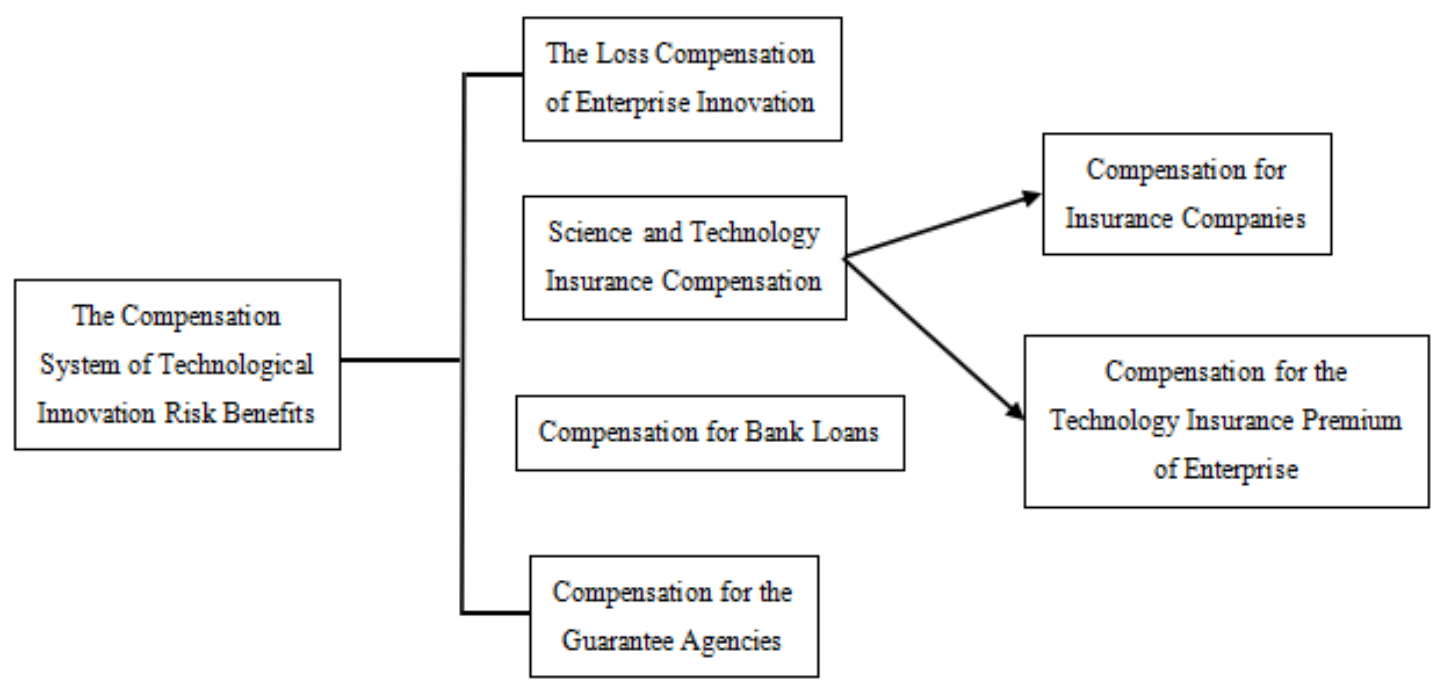

Fig.2 The Composition of Compensation System of Technological Innovation Risk

\section{The Operating Mechanism of Risk Compensation System of Technological Innovation}

The operating mechanism of the risk compensation system of technology innovation can be shown in Fig.3. In the whole technology innovation risk compensation system, the government is the subject to have investment, plan and construction, the government departments can invest some funds and part of the revenue into various types of technology innovation according to the planning system through the development of policies and systems, so as to promote their enthusiasm and initiative of participation in technological innovation. Among the various types of subjects of the participation in technology innovation, the enterprise is the most direct and the most important subject, the construction of technology innovation system in our country has clearly proposed that the enterprise should be regarded as the main body of the innovation, with the market oriented in the technological innovation system. Therefore, the most important compensation in the risk compensation system of technological innovation is the compensation for the enterprise.

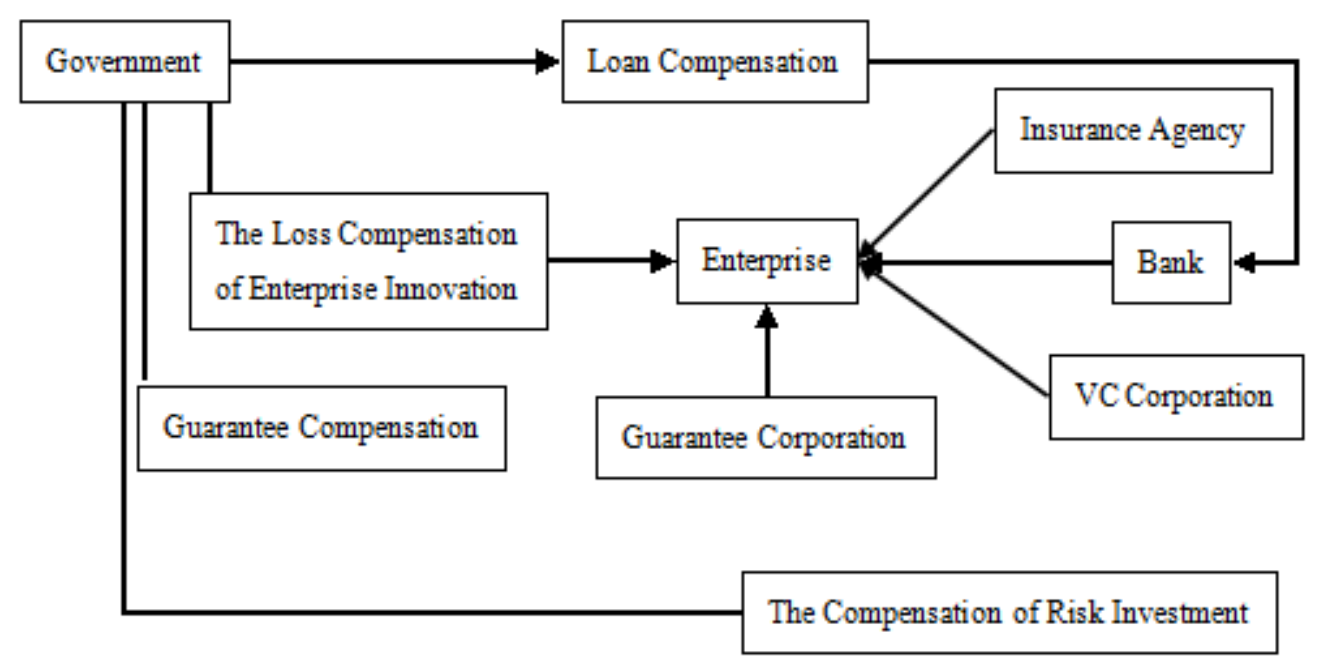

Fig. 3 The Operating Mechanism of Risk Compensation System of Technological Innovation

\section{Reference}

[1]Taylor Hazel, Artman Edward, Woelfer Jill PalzkilL 2012. Information technology project risk management; bridging the gap between research and practice. Journal of Information Technology. vol.27, pp17-34. 
[2]Graham Andrea M.,Rogers Jamie. 2011. Technology innovation risk mitigation and organizational strategy: A balanced framework for technology managers. PICMET: Portland International Center for Management of Engineering and Technology, Proceedings, IEEE Computer Society. pp1-6.

[3]Love Peter E. D., Davis Peter R., Chevis Robert, Edwards David J. 2011. Risk/Reward compensation model for civil engineering infrastructure alliance projects, Journal of Construction Engineering and Management-ASCE. vol.137, pp127-136.

[4]Beinhofer Bemhard. 2010. Producing softwood of different quality: does this provide risk compensation?. Huropean Journal of Vorosi Research. vol.129, pp921-934.

[5]James 1 Icdiund. 2000. Risky business: safely regulations, risk compensation, and individual bchavior. Injury Prevention. vol.6, pp82-90.

[6]Sen, F. K., Egelhoff, W. G., 2000. Innovative capabilities of a firm and the use of technical alliances. IEEE Transactions on Engineering Management 47, 174-183

[7] Zhu, J., 2000. Multi-factor performance measure model with an application to Fortune 500 companies. European Journal of Operational Research123, 105-124.

[8] G. Ping, X. Kefan and C. Jianfeng, 2003 “The Negotiation and Game in Enterprises Cooperation”, Journal of Industrial Engineering Engineering Management, vol. 3, pp 43-53.

[9] C. Bing, 2010 "Innovation and Industry", University and Research Institute Cooperative, Guangdong Economic Press, Guangzhou.

[10] X. Lebin, W. Xu and X. Hongbin, 2010 "Research on Risk Compensation of Benefits Distribution of Industry Technology Innovation Strategic Alliance", Journal of Statistics and Decision, vol. 14, pp 123-129. 